\title{
STRATEGIES FOR PRESERVING CULTURAL HERITAGE AND \\ CULTURAL IDENTITY IN EGYPT
}

Hoda Gad Al Rab Abdo Madkour *

Interior Design Department, College of Art and Design, October University For Modern Sciences \& Arts, Egypt

\begin{abstract}
Cultural heritage, in all its types and forms, is a source of pride and pride for nations. It is, with its values and meanings, evidence of authenticity, authenticity, and expression of the national identity, as it relates to the nation's personality and gives it its distinctive character and expresses its vitality, ability to confront and challenge, and determines its level of taste and creative sense. And the degree of progress in science and the arts. Heritage represents a link between the past and present of nations and contributes to shaping their future.

Keywords

Strategies, Preserving, Cultural Heritage, Cultural Identity, Egypt.
\end{abstract}

\section{Introduction}

It is considered a basic pillar in the economy of many countries. It is the main resource around which the tourism industry is based, and it is a fertile material for scientific research and the development of historical information. This has prompted all nations to pay attention to and protect the heritage by setting up plans and strategies, and by enacting legislations and laws to protect this heritage from various destructive factors, and by establishing educational and training programs to qualify qualified cadres to deal with this heritage in appropriate ways and methods.

The architectural cultural heritage has witnessed a state of deterioration, including a group of buildings with multiple activities that represent a national wealth and an urban façade for Egypt, as they form multiple edifices that contribute to forming the cultural and civilizational background that we are all proud of. Hence, preserving that wealth and extending its life. It must take a great deal of importance, which requires dealing with it through a scientific and organized method for the process of maintenance and preservation, which ensures security and safety, and pushes the process of preserving our national heritage forward, as the heritage environments in Egypt are formed from different levels of accumulation of architectural and cultural heritage, beginning with Pharaonic architecture And passing through the ages of the Greeks and Romans, then Islamic architecture, beginning with the Mosque of Omar Ibn AlAas, Umayyad, Tulunid, Ikhshidi, Fatimid, Ayyubid, Mamluk and Ottoman buildings, then the architecture of the Renaissance of Egypt (Muhammad Ali Pasha) with a mixture of European influence with the inheritance of the environment and then the architecture of the beginning of

*Corresponding author: info@msa.eun.eg 
the twentieth century considering that according to the law of "antiquities Any building over 100 years old is considered an antiquity that must be recorded, documented and preserved. In general, these disparate and uneven environments suffer from many problems. Including neglect, encroachment, distortions, loss of identity, visual pollution, and a mixture of chaos between buildings and the surrounding environment for the elements of site coordination of roads, sidewalks, afforestation and lighting stemming from a lack of understanding of the integrated philosophy of all these elements together with each other. Architectural cultural heritage is an honest expression of the history and culture of a society, and thus heritage is an embodiment. For cultural and civilizational values that reflect the civilizations of peoples with their religious, social, cultural and political characteristics and a socio-economic environment lived for generations. Cultural heritage includes several areas, including the built environment represented in the architectural heritage of buildings and historical cities, and there is a line connecting the different historical stages. It is this civilization line that forms the human culture and shows the environmental characteristics of the place.

\section{The problematic:}

\section{The problem is due to:}

First: There is a multiplicity of responsible parties concerned with these environments, which include governmental bodies and authorities that set up laws and regulations for managing, organizing and planning those environments of a special nature, and at the same time they are responsible for respecting, commitment and continuity of application of these laws and regulations or changing them according to personal vision and whims and without specialized studies Which reflects negatively on the urban and architectural formation of these heritage environments and the control of dissonance over their various contents. Second: Because of the same nature of the heritage environments that differ in the historical value or the functional nature of the mini or the environment that performs the original function for which it is established, re-employs or performs a tourism function), or in the case of the same heritage urban and architectural mini on the one hand, and the surrounding environment on the other side ( Is the environment in the city center and in a populated area or in an isolated or limited population), and also according to a supervisory authority, or ownership of the site or the environment, the Antiquities Authority or individuals) because there are some items of heritage buildings within the properties of either individuals or private bodies in the city center (Cairo Khedive Ismail) Which turned into uses different from what it was created for and was subjected to internal and functional adjustments, thus losing the values of architectural beauty externally and the environment associated with it. Thirdly, the negativity of society from the 
private sector and individuals whose interests are limited to a utilitarian interest and the values of beauty and the coordination of the urban environment do not occupy a space of interest, but on the contrary they had an effective role in the demolition of many architectural heritage symbols to be replaced by facilities characterized by poverty and ugliness and elements of site coordination that do not match the vocabulary of the heritage environment. Fourthly, the general public, the citizens, who represent the dangerous negative element that is lost in vision and perception and does not consist with the architectural and urban coordination processes. Therefore, awareness of the urban heritage environment, its components, beauty concepts and how to preserve it from tampering, change and attrition must be deepened. Finally, the architect and planner who performs the technical side and translates the relationships between preserving, renewing and employing the heritage environments, such as buildings, streets, and site coordination elements in line with the values of architectural accumulation, modern day technologies, and the positivistic conditions for each of these environments.

The coordination of sites and heritage environments is one of the fields of architectural and urban studies that is concerned with designing, planning and introducing various and multiple variables to those environments so that there is a homogeneous and equal unit in the process of visual presence in society and the protection of the architectural heritage wealth of a distinctive character in terms of understanding the environmental architecture that depends on the characteristics of the climate Society and history.

\section{Methodology of the research paper:}

The research paper relies on deductive analytical study to understand the principles and concepts involved in both the preservation of heritage environments and the elements of site coordination in them, with the aim of reaching a future vision of the presumed role of heritage environments through the elements of their components and inherited cultural values on the one hand and the functional and the goal of decisions and the guiding framework determinants and features Dealing, managing and implementing the coordination of functional, complementary and aesthetic sites for heritage environments of special sensitivity. The process of preserving cultural heritage is an integral part of the process of preserving human identity and this is done through the following: Maintaining the balance between achieving service, functional and aesthetic goals to purify sites and goals related to thought and permanence Preserving the heritage environments, while striving to achieve investment objectives of a service-developmental nature for the inhabitants of these environments and objectives of a service nature for visitors. Reliance on environmental resources and technologies compatible with buildings of a special nature, with the ability to self-manage elements of site coordination 
in operation and maintenance. Expanding the partnership base of decision-maker, advisory thought, the private sector and residents in developing, upgrading and re-employing heritage environments and what that includes adding elements of site coordination. Developing a vision with plans that help in the replacement and replacement of the site coordination elements in the heritage environments.

\section{The concept of preserving the architectural heritage environment and coordinating sites:}

Understanding the principles and concepts concerned regarding both the preservation of heritage environments and the elements of site coordination in them, in order to reach a future vision of the presumed role of heritage environments, it is necessary to study the elements of coordination of sites, inherited and functional values and the goal of decisions within the framework of the determinants and features of dealing and the application of coordination of functional, complementary and cosmetic sites for heritage environments With special sensitivity, we summarize this as follows:

\section{Historical spatial space:}

Heritage is the common factor among all peoples, regardless of the age of their civilization, and heritage is defined as the stock or stock of value in a society that is characterized by resilience, continuity, and community acceptance of it, whether it is from acquisitions, technologies, etc., and from this logic, the architectural heritage can be defined as everything that the ancestors built It is a cultural landmark of individual buildings or grouped buildings, whether complete or incomplete, characterized by a character and style predominant in relation to the materials or arts used in them. Architectural heritage in its comprehensive sense is represented in the following elements:

1-A comprehensive spatial environment, such as an urban agglomeration or a populated or deserted city.

2-A comprehensive site: it contains a group of buildings, squares and corridors.

3-A specific location, such as a place containing one or more buildings in a formation that has a specific visual relationship.

\section{A specific building:}

Stand alone. Most of the contemporary ancient cities have civilizations, heritage environments and archaeological buildings that preceded them and helped define their personality and civilization character, and these heritage environments suffer from a set of currents and ideas that affect the attempts of development, development, re-planning, construction, site coordination, renewal and preservation of these ancient cities and historical environments. Climatic, geographical, topographic, geological, building materials (the framework of the 
external environment of the human being, when there is an imbalance between these interconnected factors and inappropriate patterns of human life and development appear, intervention is required to address these conditions through appropriate planning and design for the data and needs of the place and the human being. The environment is embodied with what it includes. An existing urban organization that devised multiple urban patterns and functions, expressing the civilized level of renaissance and societies in the spatial space that take into account the natural and social determinants of the population, customs and traditions, historical features, cultural and economic values (economic activities, per capita income, the level of civilization), and the heritage environment contains buildings and relationships And memories are accumulated and inherited, and there are human elements in the heritage environment And different materials: people, water, air, soil, trees and plants. One of the negative aspects of the growth and development of these heritage environments is that they are affected by all the unconsidered changes, which make them lose the ability to be sustainable. Leaving them without development can lead to their loss, and unexamined work can also lead to their loss. Accordingly, these heritage environments raise some important and fundamental questions, including:

-How to preserve the urban, civilized character of heritage environments, from the level of ancient cities to regions and even historical buildings, without prejudice to them when taking any steps to develop or renew these environments.

-How to identify the achievements of the past, and the temporal and spatial development of the heritage environment and its inhabitants, and use them in planning for a better future.

-How can cities, neighborhoods, and new buildings have an urban character that combines the beauty of design, intellectual enrichment and architectural originality.

- How can we protect the freedom of the individual in choosing the appropriate architecture and the elements of coordinating functional, aesthetic and complementary sites in these particularly sensitive environments without this being at the expense of the heritage values and the general character of the environment or the area in which he resides.

What is the extent of the freedom of architectural and planning thought when adding elements of the coordination of sites and heritage environments, and on foundations and standards.

-How can these environments be employed so that they have a practical economic and cultural return (for example, in tourism) without losing the original values?

-How can an architect, planner, site coordinator, decision-maker, archaeologist, and residents of these environments work together and participate in the popular development of these environments. In order for us to answer these questions, the research paper will clarify the 
concept of preservation on the one hand and the elements of site coordination on the other hand.

\section{Preservation and renewal of historical areas and their objectives:}

Preservation means that it is an act taken to prevent the deterioration and distortion of old cities, the historical environment, or heritage buildings, and it includes all works that prolong the life of the heritage and the distinctive civilization character of those cities, environments and buildings with an understanding of the various aspects of these works, economically, socially, administratively and technically. Preservation is defined as the permanent maintenance and protection of the old city, the historical environment and the heritage buildings from encroachment, distortion and destruction that can occur with them, whether intentionally or ignorantly, and an attempt to save the old city and the historical environment and heritage buildings from losing their identity and distinctive architectural character, not with the aim of impeding the movement of growth, development and progress, but on, The basis is that the new must be a continuation of the original character of the heritage and historical content, and also preserving the art of harvesting the heritage of former nations and preserving the distinct and appropriate elements and employing them for use. Preservation includes the following set of operations: repair and restoration, protection, rehabilitation, re-employment, and comprehensive renewal, and preservation is the previous processes in addition to a study to ensure that it does not have a negative impact on it, as it is possible for EIA to evaluate the environmental impact of projects after applying the preservation of a city or heritage buildings. In a historical area that a deterioration occurs to it or it again because the environmental impact assessment studies have not been done and the preparation of the environment or buildings to accept conservation processes Why conservation:

\section{There are many reasons that lead to preservation, including:}

Social and historical: It is a need for the continuation of the social function and linking it to the memories of the occupants of the old city, which are the embodiment of historical events and periods and personalities that have their influence on events and the translation of special living phenomena that give a continuation of the cultural spring through the ages.

-Economic: The tourism function of urban heritage is an important source of income, as in Morocco and Turkey, with the possibilities of reusing the preserved areas, whether as shrines or cultural museums, and in the preservation areas and ancient cities the artistic, philosophical and technical values in addition to the inscriptions and materials used, which are considered an invaluable wealth of materials Limited.

Political: Through preservation, it is possible to learn from the past and narrate history with great events and an expression of the political situation controlling those cities during periods 
of the values of governance, its strength, strength and stability. Religious and ideological: It is represented in setting religious values in urban groups such as places of worship, residences, markets and others.

-Continuous development is to work on the continuation of the inherited ideas in urban groups that serve as a guide for future generations. Preservation aims to:

-Urging the development of a degree of historical awareness, which is a prerequisite for any future change in the heritage urban environments.

Understanding the spirit of civilization that dominates the historical urban environments and integrating the content of the past with the components of the place, the genes of time, its present and its future in a distinct unity that gives a sense of continuity. - Delivering the artistic, cultural, humanitarian and civilizational messages contained in ancient cities, historical environments and heritage buildings to future generations in a good way.

-The aim of preservation should not be the prevention and maintenance only, or the exploitation of the historical built environments in tourism, so that the heritage components are not the Zoo Human Museum), but rather the residents participating in the conservation operations must be invited as they are the first to benefit. Whereas, public participation is the practical and realistic key to all conservation processes.

\section{-Coordination of sites and objectives associated with historical environments.}

The elements of site coordination (landscape) is a basic necessity for urban environments in general and the historical environment that is particularly sensitive, so that it can perform the vital functions expected of it, whether for actual use or adding an aesthetic dimension to the environment and buildings or by integrating with the vocabulary of the original environment, and the site coordination elements express the general impression and not On the vocabulary and details of the general view, but how these vocabulary will work in general is distinctive in its general thought, and at the same time it derives details of its association with the environment from the formation of the land, agriculture, buildings and the historical idea expressed, implicitly with the rest of the cultural components, whether related to public use or related to inanimate elements (From furnishing and organizing) or related to plants. It is imperative to understand what the components are and the requirements for the design and coordination elements of the sites so that we can study how to employ them or beautify them and their integration with historical environments. The objectives of site coordination can be accomplished in the renewal and preservation of historical environments as follows: Planning to overcome the determinants of urbanization (air - water - land ...) and living determinants such as (plants, wildlife and wildlife) while respecting the specificity of the environment, which 
are goals that constitute measures of planning goals To give the layout more distinction within the normal schematic sequence.

Not only in order to protect the landscape or preserve the local character, but to ensure that the negative impact is from the least in terms of hydrological, air pollution, or other pollutants, is the least. Increasing the interdependence between urban and rural urban areas and between built-up areas and proposed areas within the framework of achieving strategic goals and local goals at the same time. Add coordinating sites to give appropriate treatments for spaces to be implemented in building an appropriate environment. Curatorial Museum, in which the landscape elements of the site are preserved from daily use, deterioration, or cultural value, and the site is preserved from potential dangers. Investment Exploitation Direct objectives without affecting the character, including: cleanliness of the site so that it is acceptable to view, facilitate entry and exit processes, provide a convenient service for users and ensure the ease and safety of users.

\section{Legal procedures and regulations related to the historical environment:}

General procedures (conferences - recommendations, regulations) recommendations of the Venice Conference, one of the most important conferences that occurred in Italy in the year 18 as a result of the serious violations that were exposed to buildings and the historical fabric there, the most important of these recommendations were the following:

-Preserving the architectural features from any additions and the method of maintenance and repair must be adopted, not restoration: the new additions to the historic building or the construction of ruined parts in case of urgent necessity, these additions must preserve their new character distinct from the original building, while making sure that the new shape fits perfectly with Origin: All the elements that have been added to the mini are also considered architectural features during different periods of time that have changed the features of the original building, with the exception of those additions of modest value that negatively affect important parts of the building: the building to be preserved must be photographed and recorded before and during all The periods to which it is subjected to repairs, and these photos must be sent, along with the diagrams and illustrative colors of the preservation work, to the institutions concerned with monitoring the course of implementation, and a full explanation of the work of installation, support, change, removal and demolition

\section{Conclusion and recommendations:}

In light of these difficult situations, we find that we, as researchers and specialists in urban planning, are responsible, albeit relatively, for what is happening in relation to our civilized history, and this responsibility must be crystallized in theory and process in order to stand in 
front of the obstacles that may lead to the loss of our identity and to establish our roots, using all available capabilities, whether from political, organizational or In this context, the role of the urban planner and the architect in defining frameworks, provisions and policies to control the process of preserving historical environments is highlighted in this context.

1-Assessment and conclusions of planning in the historical environment:

2-The concept of schematic fit is different from dealing with other formats, as it goes beyond the A-types and requires solutions stemming from each region and its circumstances.

3-Overcoming the concept of traditional arrangement in the spatial distribution patterns of services and roads, for example the concept of gradation of road widths can be overlooked, but the priority may be logical connection points that allow unimpeded access.

4-Verifying the requirements for public use as a service or production project, even if it faces difficulties with environmental approvals in light of the limited available lands, for example monitoring spaces that do not harm the historical scope may be suitable for the exploitation of maintenance or other development projects.

5-The scientific formation of local rules for legislation is not harmonized and requires models that suit flexible dealings with historical regions.

\section{Urban and Architectural Renewal Recommendations:}

1-Recasting the general aesthetic vision of all historical environments, removing the current encroachments and distortions, preserving the general character of architecture, respecting the architecture in which the buildings are designed, and setting controls to ensure that there is no change in the existing architectural form to prevent additions to existing buildings that lead to their distortion.

2-Recasting the historical environments according to the visual architectural vision that is consistent with the general characteristic of each region, preserving its old squares and the distinguished ancient architectural elements, and restoring its original image.

3-Laying down foundations for how to deal with exposed architectural vacuums such as gardens, streets, sidewalks, means of advertising, lighting, and colors to be confirmed to distinguish each historical area.

4-Preparing civilized projects to replace slums with historical environments, as well as setting standards for each neighborhood in proportion to its distinctive features, so that neighborhoods in their entirety form the specific features of each region.

\section{Recommendations for coordinating sites in historic areas:}

1-Preserving the special impact of the historical environment One of the most important elements of coordination projects is sites that must be taken into account. The elements of site 
coordination must be derived from the activities in which they take place in the historical environment.

2-Diversity in choosing suitable plants that will be planted in the area, along with trees that have historical roots linked to the historical region, with the need to set an awareness program for the people and interest in popular participation and to clarify the importance of the impact and the great efforts exerted in preserving it so that they participate in preserving the antiquity and love it and protect the region from factors Degradation, destruction and contamination.

3-Putting in place controls that require the implementation of floor treatment in accordance with internationally recognized standards, respecting pedestrians and the handicapped, with the use of materials commensurate with the architectural character of each historical area.

\section{Recommendations for future studies and research:}

1-The importance of developing architectural education and strengthening the technical capabilities of workers in the field of antiquities restoration, whether they are companies, restorers or engineers, preparing technical personnel to work and preserving the right of antiquities and preserving antiquities as it is without addition or imitation. Material, craft and design are the primary value in what humans have done for thousands of years. His creativity and creativity must be preserved to preserve the heritage value.

\section{References:}

1- Hisham, Ali Mahran, "Green Architecture and Cities of a Healthy Environment," Journal of Science - Chapter of the Ecologist - Issue 243 - Cairo - Arab Republic of Egypt - August 12

2- Tariq Muhammad Wali: Reviving the Urban Heritage of the Islamic City, Topic Five, Conference on Preserving the Islamic Architectural Heritage in Cities, Istanbul, Turkey, 19 , p. 151.

3- Saleh Lamai Mustafa: Architectural Restoration of the Cultural Heritage, Upgrading the Built Environment of Cities, First Edition, Dar Al-Shorouk Press, Cairo, 19, p. 55

4- Ali Mahmoud Bayoumi: Urban Development and Heritage Preservation: A Study on the City of Rashid, Master Thesis, University of Alexandria, Department of Architecture, College of Engineering, 120 p. 4

5- Abdulaziz Al-Dawlanli: Why and How to Preserve the Old Arab City, Researches of the Arab City Symposium. Arab Development Institute Publications, Cities, Washington, USA, 12, p. 51

6- Amani El-Sayed Abdel-Rahman Ahmed Al-Rayyes, Urban Revitalization as a Pillar of Sustainability with a Special Mention of Areas Urban Heritage, PhD Thesis, Cairo 
University, 2010

7- Joyce, Tatt, Andrew Lane \& Susan Carr, "Practical Conservation Site Assessment and Management Planning, HRH the Prince of Wales, the Open University, 1988.

8- Tillman, John L, "Design for human ecosystems", van nostrand Reinhold Company, New York, 1999.

9- Jhon Ruskin, "le Sette Lampade dell'Architettura", Jack Book, Milano, p.24. 1997.

10- G. Carbonara, "Restaoro dei monumenti, Guido agli elaborati grafici", Napoli, Liguori, 1990.

11- Jhon Ruskin, "le Sette Lampade dell'Architettura", Jack Book, Milano, 1997, p.24.

12- Reeve, D. E. and Patch, J. R. "GIS, Organizations and people A Sociotechnical Approach", Taylor \& Francis Ltd., London, UK, 1999.

13- Yeh, A, "Urban Planning and Geographical Information Systems", Volume 2, second edition, Management Issues and Applications, john Wiley \& sons, Inc., USA, 1999.

14- Akhbar al-Adab: "Restoration Mistakes Threatening 30 Archaeological Sites in Islamic Cairo", Year 2, Issue 436, Sunday November 12, 2001 AD.

15- Fuad, Sakina: "Protecting antiquities is an individual duty on every Egyptian", The Book, Issue 1900, Year 124, Thursday, 20 September 19.

16- Muhammad Abu Al-Mahasen Asfour, Landmarks in the History of the Ancient Near East, Dar Al-Nahda Al-Arabiyya, Beirut, Lebanon, 2010. 12- Hammad Muhammad, Humanitarian Town Planning through the Ages, Egyptian General Book Authority, Cairo, 2009.

17- Wilkinson. Richard H., "The Complete Temples of Ancient Egypt", London, 2000.

18- Rapoport, Amos, "An approach to vernacular design", paper 24, in book of 33 papers environment behavior research, the urban international press, 1998.

19- Lorenza Di Pilla, A Mindful Choice of Building Materials: A Keen Application of the 4Rs of Resilience, International Journal of Architectural Engineering and Urban Research, Vol. 1, No. 2, 2018, pp. 1-17.

20- Hala S. Mahdi, Cultural Heritage and its Role in Enriching Egyptian Architecture, International Journal of Architectural Engineering and Urban Research, Vol. 1, No. 1, 2018, pp. 20-25. 